\title{
Efficacy of Moderate Aerobic Training on Insulin Like Growth Factor and Functional Capacity in Elderly
}

\author{
SHYMAA Y. ABO ZAID, M.Sc.*; SAMAH M. ISMAIL, Ph.D.**; MARIAM E. MOHAMED, Ph.D.*** and \\ FARAG A. ALY, Ph.D.*** \\ The Department of Physical Therapy for Cardiovascular/Respiratory Disorder \& Geriatrics, Faculty of Physical Therapy, \\ South Valley*, Cairo** and Horus*** Universities
}

\begin{abstract}
Background: The Insulin like Growth Factor-1 (IGF-1) decrease with aging, which lead to several disorders and disabilities in elderly.

Objective: The purpose of this study was to find out the effect of moderate aerobic training on insulin like growth factor and functional capacity in elderly.

Subjects and Methods: The study was conducted on thirty elderly subjects, their age ranged from 65 to 75 years old with mean value of 64.81 years, they were selected randomly based on the inclusion criteria. All the subjects had participated in moderate aerobic training calculated as $60 \%$ to $70 \%$ of their predetermined maximum heart rate. This program was applied three times per week for eight weeks.

Results: Statistical analysis showed a significant increase of insulin like growth factor by $32 \%$ and functional capacity by $18.5 \%$.

Conclusion: It was concluded that moderate aerobic training improve insulin like growth factor and functional capacity in elderly.
\end{abstract}

Key Words: Elderly - Aerobic training - Insulin like growth factor-Functional capacity.

\section{Introduction}

MANY studies found that Growth Hormone (GH) and Insulin like Growth Factor-1 (IGF-1) decrease with age and that administration of these hormones decrease the deterioration of tissue function that founded in aged and libitum fed animals, suggesting that absence of these hormones contributes to the phenotype of aging [1]

Correspondence to: Dr. Shymaa Y. Abo Zaid, The Department of Physical Therapy for Cardiovascular/Respiratory Disorder \& Geriatrics, Faculty of Physical Therapy, South Valley University
In addition, it is founded that IGF-1 is a main source in restoring mitochondrial dysfunction during aging by enhancing mitochondrial membrane potential, decreasing oxygen consumption, and increasing ATP production that lead to minimizing the c-cytochrome release to the cytoplasm and increasing neural survival by reducing caspaseinduced apoptosis [2-4].

Also, IGF-1's antioxidant ability in brain cortex and hippocampus was assessed as increasing antioxidant enzymes activities (superoxide dismutase, catalase and glutathione peroxidase) and parameters of oxidative damage (MDA and PCC) [3,4] .

Insulin like growth factor-1 has been found as an index of healthy aging, because of the finding that it directly correlates with the leukocyte telomere length [5].

The age-related decline in maximal strength and maximal oxygen uptake need older adults to work at their best for performing ADL [6]

The ability to perform Activities of Daily Living (ADL) is important to a sufficient health-related quality of life. The cause of functional disability is complex; however, a primary aetiology to this is sarcopenia-the age-related loss of muscle mass and quality-and a cardiovascular system dysfunction [7].

It is important to find out a way that will address functional decline by reducing the decline in both the muscular and cardiovascular systems and enhancing the quality of life for elderly [8]. Therefore the purpose of this study was to investigate the influence of moderate aerobic training on insulin like growth factor and functional capacity in elderly. 


\section{Subjects and Methods}

\section{I- Subjects:}

Thirty elderly subjects of both sexes were participated in this study. Their age ranged from 6070 years old with a mean value of 64.18 years. Their Body Mass Index (BMI) ranged from 25$29.9 \mathrm{~kg} / \mathrm{m}^{2}$ and they were sedentary (not participating in regular aerobic or strengthening exercise over 6 months prior to entering the study). They were selected randomly from Qena University Hospitals, in May 2016. Subjects who have history of serious cerebrovascular, cardiovascular diseases or musculoskeletal problems restricting their physical activity, chronic (respiratory, kidney, liver, metabolic and neurological) disorders were excluded from the study.

All subjects were thoroughly evaluated before and after the treatment protocol application. Participants were prepared for a baseline assessment, which included measurements for body weight, body height, IGF-1 and functional capacity. The measurements were taken at the beginning and at the end of the study. The study was conducted in the Outpatient Clinic of Qena University Hospitals, Egypt.

II- Methods:

\section{A- For evaluation:}

- Radioimmunoassay kits: Count-A-Count; DPC, Los Angeles, CA for IGF measuring.

- Six-minute walk test (6-MWT): To measure functional capacity.

- Height and weight scale: (Floor type model ZT-120, made in china): It was used to measure the height and the weight of each subject, to be used as a data base for six minute walk test and to calculate BMI.

- Mercury Sphygmomanometer: (Diplomat, Presameter made in Germany) and stethoscope (Riester, duplex, made in Germany). It was used to measure the blood pressure before and after each exercise training session.

- Pulsometer: (Tunturt TPM-400, made in Japan) it was used to detect the pulse rate before and after exercise, and to control the exercise intensity within the pre calculated training heart rate during every exercise session.

\section{B- For training:}

Electronic treadmill: (Enraf Nonius, EN-TRE, made in Germany), its speed, inclination and timer are adjustable, and it also provided with control panel to display the exercise parameters.

\section{III- Procedures:}

The study protocol was explained in details for every subject before the initial assessment. A complete history and physical examination were taken for all subjects. A written informed consent was signed by each subject before participation in the study as an agreement to be included in the present study.

The study was reviewed and approved by the Ethics Committee of Faculty of Physical Therapy Cairo University.

\section{Evaluated parameters:}

- A somatomedin C test or insulin like growth factor test: Blood samples were obtained from an antecubital vein in the morning following overnight fasting, prior to training, and another time after the end of 8 weeks of aerobic exercises, serum IGFI were measured by radioimmunoassay kits. The intra-and interassay coefficient variations were $3.9 \%$ and $2.8 \%$ for IGFI.

- Six minute walk test (6 MWT): The walking course is laid out in a 50 yard $(45.72 \mathrm{~m})$ rectangular area (dimensions 45 X 5 yards), with cones placed at regular intervals to indicate distance walked. The aim of this test is to walk as quickly as possible for six minutes to cover as much ground as possible. Subjects set their own pace (a preliminary trail is useful to practice pacing), and abled to stop for a rest if they desired, for scoring: Measure the distance walked in 6 minutes to the nearest meter [9]

\section{Exercise training program:}

Every subject performed moderate aerobic training program three times per week for eight weeks using treadmill. The exercise intensity had been prescribed as a Training Heart Rate (THR) depending on each subject's maximum heart rate (HR max), and resting heart rate (HR rest) gained from the exercise test, and calculated according to Karvonen formula as follow THR $=$ HR rest + $(\mathrm{HR}$ max $-\mathrm{HR}$ rest $) \mathrm{TF}, \mathrm{TF}=$ training fraction, it was $60-70 \%$ in moderate training [10]

Each subject started the training session by warming up exercise for 5-10 minutes in the form of stretching exercise, marching or even walking on treadmill with heart rate of $30-40 \%$ of the HR max to adapt cardiopulmonary system, decrease formation of lactic acid and to decrease the risk of decline in blood pressure, cardiovascular and musculoskeletal complications [11]. Warming up phase followed by active phase during which the speed increased gradually until the range of $60-70 \%$ of 
HR max of the subject for 30 minutes, then the exercise finished by cooling down by gradual decreasing of treadmill speed to prevent postural hypotension [12]. Pulse rate had been continuously observed during the training session. Subject instructed to report any significant symptoms he feels during the session to the physiotherapist [13]

\section{Statistical procedures:}

In this study collected data were fed to the computer, manipulated and analyzed using (SPSS under win; statistical package, Version 10, 1998). Descriptive statistical analysis, in the form of mean, standard deviation was calculated for all pre and post training variables. The comparison was made by $t$-test to determine the probability levels for differences in the mean values between the results observed before and after the training program. Statistical significance was established at the conventional $<0.05$ level.

\section{Results}

The purpose of this study was to find out the efficacy of moderate intensity aerobic training on IGF-1 and functional capacity in elderly.

\section{A- Subjects general characteristics:}

Table (1): General characteristics of all study participants.

\begin{tabular}{lcccc}
\hline $\begin{array}{l}\text { Statistical } \\
\text { tools }\end{array}$ & $\begin{array}{c}\text { Age/ } \\
\text { year }\end{array}$ & $\begin{array}{c}\text { Height/ } \\
\mathrm{cm}\end{array}$ & $\begin{array}{c}\text { Weight/ } \\
\mathrm{Kg}\end{array}$ & $\begin{array}{c}\text { Body mass } \\
\text { index }\end{array}$ \\
\hline Mean \pm SD & $64.18 \pm 2.959$ & $161.36 \pm 8.791$ & $68.83 \pm 9.039$ & $21.3 \pm 32.9$
\end{tabular}

\section{$B$ - Analysis of the results of Insulin like growth} factor 1:

Table (2): Comparison between Insulin like growth factor 1 results before and after the treatment.

\begin{tabular}{lcc}
\hline \multirow{2}{*}{ Statistical tools } & \multicolumn{2}{c}{ Study group } \\
\cline { 2 - 3 } & Before treatment & After treatment \\
\hline Mean \pm SD & $100.722 \pm 31.156$ & $132.923 \pm 36.195$ \\
Mean difference & -32.201 \\
$\%$ of improvement & $31.97 \%$ \\
$t$-value & -15.519 \\
$p$-value & 0.000 \\
\hline
\end{tabular}

C-Analysis of the results of six minute walk test in the study group:

Table (3): Comparison between six minute walk test results before and after the treatment.

\begin{tabular}{lcc}
\hline \multirow{2}{*}{ Statistical tools } & \multicolumn{2}{c}{ Study group } \\
\cline { 2 - 3 } & Before treatment & After treatment \\
\hline Mean \pm SD & $424.700 \pm 48.046$ & $503.438 \pm 56.663$ \\
Mean difference & \multicolumn{2}{c}{-78.738} \\
\% of improvement & $18.540 \%$ \\
$t$-value & -15.242 \\
$p$-value & 0.000 \\
\hline
\end{tabular}

\section{Discussion}

This study was conducted to find out the effect of moderate aerobic training on insulin like growth factor and functional capacity in elderly, thirty elderly subjects were participated in this study, each subject of this study had participated in aerobic training of moderate intensity with training fraction of $65 \%$ to $75 \%$ of each subject's maximum heart rate, this program were applied three times per week for 8 weeks. The result of this study revealed that 8 weeks of supervised aerobic exercise training produced a significant increase in insulin like growth factor with a percentage of $32 \%$, and increase in functional capacity with a percentage of $18.5 \%$.

Insulin like growth factor-1 response to either acute or chronic exercises remains un obvious, while some studies have founded no alternation in circulating IGF-1 levels, in many others exercise induced a transient increase in IGF-I levels resulting from acute release of IGF-1 from its binding proteins [14]

Current study was supported by findings of Sagiv et al., [15], who found that increased levels of IGF-1 have been found in physically active compared to sedentary subjects, also they founded that IGF-1 as a mediator plays a very important role in muscle hypertrophy and angiogenesis, both of which characterize the anabolic adaptation of muscles due to exercise.

Based on many studies done in healthy young adults, there was an increase in circulating IGF-1 in response to various types of exercise either aerobic, resistance, or heavy ergometer cycling, that supported current study findings [16]

Hambrecht et al., [17], suggested that exercise training improves local IGF-1 expression without significant changes of systemic parameters of the GH-IGF-1 axis. These findings indicated that exercise training has the therapeutic potential to decrease peripheral skeletal muscle changes in particular with respect to local IGF-1 expression in patients with moderate cardiac heart failure.

IGF-1 response depends on exercise type, duration, and intensity as well as training status [18]

Amir et al., [19], had suggested that at rest, circulating IGF-1 in the trained were lower by $17 \%$ in comparing with the untrained older individuals.

It may be suggested that the changes in IGF1 and Fibroblast Growth Factor-2 (FGF-2) may have positive anabolic effects on the induction of 
muscle and capillary growth, resulting in muscle hypertrophy and angiogenesis. So, the fitnessinduced change in IGF-1 and FGF levels may reverse the process of skeletal muscle loss, by modulating their positive anabolic influences, on skeletal muscle. This may have clinical effects during aging in which the decreased activity of growth factors is a major determinant of the loss of muscle strength and function. Therefore, during aging, the fitness level can change circulating levels of IGF1 and FGF-2 and can affect the response of both mediators to all-out aerobic, anaerobic and resistive exercises [15].

Adamo \& Farrar, [20], found that exercise lead to increases in IGF-1, IGF-1 receptors, and IGF1 -activated signaling pathways. Although there is evidence that the aging muscle maintains the ability to synthesize IGF-1, there is also evidence that aging may be related to reduction of the ability of exercise to induce an isoform of IGF-1 that promotes satellite cell proliferation. Also, the aging muscle may be resistant to IGF-1, an effect that is reversed by exercise. However, it is clear that the overexpression of IGF-1 in the muscle can protect against age-related sarcopenia.

Intense running lead increases in total IGF-1 concentrations, which differs from findings in past studies using less rigorous running systems and less frequent blood sampling regimens. So, running exercise that lead to substantial increases in $\mathrm{GH}$ does not affect peripheral ghrelin levels; although, significant relationships between ghrelin and both IGF-1 and Insulin growth factor binding protein3 founded during intense intermittent running and recovery, which need further investigation [21].

Current study is different from that of Adrian S. et al., [22] , that found a significant differences between groups in IGF-1 $(7.4 \mathrm{ng} / \mathrm{ml} ; p=0.045)$ after 15 weeks of exercises on cycle ergometers three times per week.

Another study of Anne McTiernan, [23], suggested that moderate-intensity aerobic exercise does not affect concentrations of IGF-1, IGFBP3 , or their ratio in overweight/obese previously sedentary postmenopausal women after 12-month moderate-intensity exercises.

Current findings come in accordance with the study of Jenniefer et al., [25], in which they found that older men and women who done at least a moderate amount of physical activity (around $400 \mathrm{kcal} / \mathrm{d}$ ) have better physical function independent of demographic and health-related factors than persons who are less active. Who performed regular exercise (30 minutes of moderate-intensity activity on most days of the week) reported greater functional capacity than those who expended similar amounts of energy but performed less-intensive physical activity. In other words, older adults who do regular exercise activities appeared to derive additional benefits for physical functional capacity that were not conferred from physical activity from doing daily chores and normal walking.

Short et al., [26], found that that repeated bouts of moderate intensity aerobic exercise enhance muscle protein synthesis in both young and elderly irrespective of age.

Also in the study of Jozsi et al., [27], reported that the muscle of older men undergoes significant increases in muscle protein turnover in response to aerobic exercise to a similar extent to that of younger men from rest to $10 \mathrm{~min}$ post exercise. When post exercise variables such as protein synthesis, protein breakdown, and leg blood flow between younger and older men are compared, it demonstrated that the older men have a more prolonged response to the exercise.

Inability to maintain physical function with advanced age is mainly contributed to several key factors as physical inactivity [28]

\section{Conclusion:}

Based on the findings of this study, it could be concluded that there is an improvement in the level of IGF-1 and functional capacity in elderly after moderate intensity aerobic training, hence decreasing the disability in geriatrics.

\section{References}

1- MOVERARE-SKRTIC S., SVENSSON J., KARLSSON M.K., ORWOLL E., LJUNGGREN O., MELLSTROM D. and OHLSSON C.: Serum insulin-like growth factorI concentration is associated with leukocyte telomere length in a population-based cohort of elderly men. J. Clin. Endocrinol. Metab., 94 (12): 5078-84, 2009.

2- HODGE R.D., D'ERCOLE A.J. and O'KUSKY J.R.: Insulin-like Growth Factor-I (IGF-I) inhibits neuronal apoptosis in the developing cerebral cortex in vivo. International Journal of Developmental Neuroscience: J. the International Society for Developmental Neuroscience, 25 (4): 233-41, 2007.

3- GARCIA-FERNANDEZ M., DELGADO G., PUCHE J.E., GONZALEZ-BARON S. and CASTILLA CORTAZAR I.: Low doses of insulin-like growth factor I improve insulin resistance, lipid metabolism, and oxidative damage in aging rats. J. Endocrinology, 149 (5): 2433-42, 2008.

4- PUCHE J.E., GARCIA-FERNANDEZ M., MUNTANE J., RIOJA J., GONZALEZ-BARON S. and CASTILLA CORTAZAR I.: Low doses of insulin-like growth factor- 
I induce mitochondrial protection in aging rats., J. Endocrinology, 149 (5): 2620-7, 2008.

5- BARTKE A.: Role of the growth hormoneinsulin-like growthfactor system in mammalian aging, J. Endocrinology, press.endocrine.org., 22: 110-2, 2005.

6- ASHER L., ARESU M., FALASCHETTI E. and MINDELL J.: Most Older pedestrians are unable to cross the road in time: A cross-sectional study. J. Age Ageing, 41: 690-4, 2012.

7- BUFORD T.W., MACNEIL R.G., CLOUGH L.G., DIRAIN M., SANDESARA B., MANINI T.M. and LEEUWENBURGH C.: Active muscle regeneration following eccentric contraction-induced injury is similar between healthy you and older adults. J. Appl. Physiol., 12: 2058, 2013.

8- SHEPHARD R.: Maximal oxygen intake and independence in old age. Br. J. Sports Med., 43: 342-6, 2009.

9- LIPKIN D.P., SCRIVEN A.J., CRAKE T. and POOLEWILSON P.A.: Six minute walking test for assessing exercise capacity in chronic heart failure. J. Br. Med. Clin. Res., 292: 653-5, 1986.

10- QUELL K.J., PORCARI J.P. and FRANKLIN B.: Is Brisk Walking An Adequate Aerobic Training Stimulus For Cardiac Patients? J. Chest, 112: 1852-6, 2002.

11-NIED R.J. and FRANKLIN B.: Promoting and Prescribing Exercises for the Elderly, J. American Academy of Family Physicians, 30: 419-26, 2002.

12- POLLOCK M.L., GAESSER G.A. and BUTCHER J.D.: American College of Sports Medicine Position Stand: The recommended quantity and quality of exercise for developing and maintaining cardio respiratory and muscular fitness and flexibility in healthy adults, J. Med. Sci Sports Exerc., 30: 975-91, 1998.

13- FARAG A. ALY, AKRAM A. EL-SAED and KHALED F. HATAB: Efficacy of Moderate Exercise Training on Cardiopulmonary Fitness among Elderly Women, J. Bull. Fac. Ph. Th., Cairo Univ., 13 (1): 27, 2008.

14- KRAEMER W.J. and RATAMESS N.A.: Hormonal responses and adaptations to resistance exercise and training. J. Sports Med., 35: 339-61, 2005.

15- SAGIV M., YAMIN C., AMIR R. and YENON N.: Alterations in IGF-I affect elderly: Role of physical activity, Eur. J. Rev. Aging. Phys. Act., 84, 4: 77, 2007.

16- RUBIN M.R., KRAEMER W.J., MARESH C.M., et al.: High affinity growth hormone binding protein and acute heavy resistance exercise. J. Med. Sci. Sports Exerc., 37: 395-403, 2005.

17- HAMBRECHT R., SCHULZE P.C., GIELEN S., et al. Effects of exercise training on insulin-like growth factorI expression in the skeletal muscle of non-cacectic patients with chronic heart failure. Eur J. Cardiovasc. Prev. Rehabil., 12: 401-6, 2005.

18- ROSENDAL L., LANGBERG H., FLYVBJERG A., FRYSTYK J., ØRSKOV H. and KJAER M.: Physical capacity influences the response of insulin-like growth factor and its binding proteins to training. J. Appl. Physiol., 93: $1669-75,2002$

19-AMIR R., BEN-SIRA D. and SAGIV M.: IGF-I and FGF2 responses to Wingate Anaerobic Test in older men. J. Sports Sci. Med., 6: 227-32, 2007.

20- ADAMO M.L. and FARRAR R.P.: Resistance training, and IGF-1 involvement in the maintenance of muscle mass during the aging process. J. Ageing. Res. Rev., 5: 310-31, 2006

21- KRAEMER R.R., DURAND R.J. and ACEVEDO E.O.: Rigorous running increases growth hormone and insulinlike growth factor-I without altering ghrelin. J. Exp. Biol. Med., 229: 240-6, 2004.

22- ADRIAN S., KERRY S., CATHERINE J., GORDON J., LEE W. and JOHN R.: Effects of Exercise Training on Fasting Insulin, Insulin Resistance, Insulin-like Growth Factors, and Insulin-like Growth Factor Binding Proteins in Postmenopausal Breast Cancer Survivors, A Randomized Controlled Trial, 12: 721-7, 2003.

23- ANNE M., BESS S., YUTAKA Y., SHELLEY S., et al.: No Effect of Exercise on Insulin-Like Growth Factor 1 and Insulin-Like Growth Factor Binding Protein 3 in Postmenopausal Women: A 12-Month, The Fred Hutchinson Cancer Research Center, 4, 4: 1020-1, 2005.

24- ORENSTEIN M.R. and FRIEDENREICH C.: Review of physical activity and the IGF family. J. Physical Activity \& Health, 1: 291-320, 2004.

25- JENNIFER S.B., ELEANOR M.S., STEPHEN K., KRISTINE Y. and ANNE B.N.: The Association Between Physical Function and Lifestyle Activity and Exercise in the Health, Aging and Body Composition Study. Am. Geriatr. Soc., 52: 502-9, 2004.

26- SHORT K.R., VITTONE J.L., BIGELOW M.L., PROCTOR D.N. and NAIR K.S.: Age and aerobic exercise training effects on whole body and muscle protein metabolism. Am. J. Physiol. Endocrinol. Metab., 286: E92E101, 2004

27- JOZSI A.C., DUPONT-VERSTEEGDEN E.E., TAYLORJONES J.M., EVANS W.J., TRAPPE T.A., CAMPBELL W.W. and PETERSON C.A.: Aged human muscle demonstrates an altered gene expression profile consistent with an impaired response to exercise, J. Mech. Ageing. Dev., 120: 45-56, 2000.

28- MORLEY J.E., BAUMGARTNER R.N., ROUBENOFF R., MAYER J., and NAIR K.S.: Sarcopenia, J. Lab. Clin. Med., 137: 231-43, 2001. 


\section{تآثير التمرينات الهوائية متوسطة الشدة على الثماتى

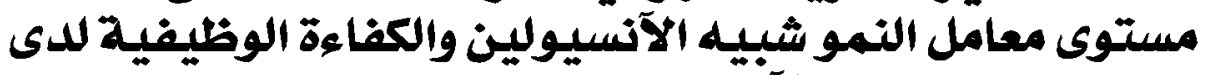 الآشخاص كبارى السن}

المستخلص: تهدف هذه الرسالة إلى دراسة تاتثير التمرينات الهوائية متوبطة الشدة على معامل النمو شبيه الآنسيولين والكفاءة الوظيفية

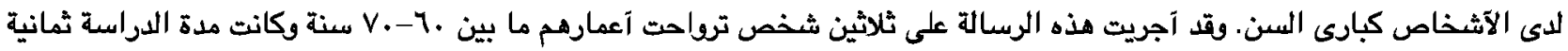

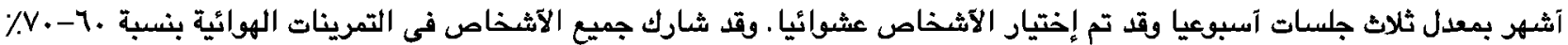

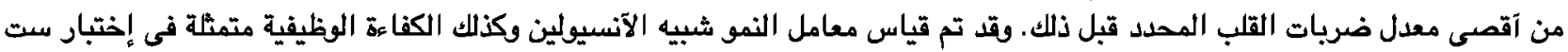

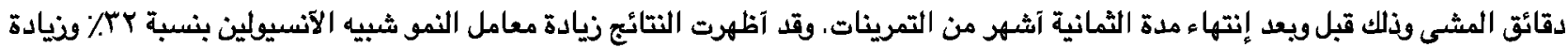

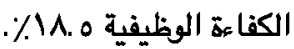

